\title{
Effect of Varenicline on Tardive Dyskinesia: A Pilot Study
}

\author{
Stanley N. Caroff ${ }^{1,2}$, Alisa R. Gutman ${ }^{1}$, John Northrop ${ }^{1}$, Shirley H. Leong ${ }^{1}$, Rosalind M. Berkowitz ${ }^{1}$, \\ E. Cabrina Campbell ${ }^{1,2}$
}

${ }^{1}$ Behavioral Health Service, Corporal Michael J. Crescenz VA Medical Center, ${ }^{2}$ Department of Psychiatry, University of Pennsylvania Perelman School of Medicine, Philadelphia, PA, USA

Objective: Although evidence implicates striatal cholinergic impairment as a mechanism underlying tardive dyskinesia, trials of nonspecific cholinergic agents have been inconclusive. As a partial agonist at specific nicotinic receptor subtypes, varenicline reduces drug-induced dyskinesias in animal models suggesting promise as a treatment for tardive dyskinesia.

Methods: Three schizophrenia patients with tardive dyskinesia who were smokers underwent an open trial of varenicline. After a 2-week baseline, subjects received varenicline $1 \mathrm{mg}$ twice daily. Changes from baseline on the Abnormal Involuntary Movement Scale were measured after a 4-week varenicline stabilization period, and 6 weeks after the smoking quit date in one patient.

Results: Varenicline had no effect on mean Abnormal Involuntary Movement Scale scores after 4 weeks. Although smoking decreased after 4 weeks on varenicline and diminished further in one patient after 10 weeks, this also appeared to have no effect on ratings of tardive dyskinesia.

Conclusion: In contrast to animal models, no significant change in tardive dyskinesia occurred in response to varenicline replacement in three schizophrenia patients. Further investigations of cholinergic mechanisms in tardive dyskinesia are worthwhile as agents for specific cholinergic targets become available for treatment. In addition, treatment trials of tardive dyskinesia should control for smoking status, while patients on antipsychotics receiving nicotine replacement therapies for smoking should be studied further for changes in movement.

KEY WORDS: Tardive dyskinesia; Smoking cessation; Varenicline; Movement disorders; Antipsychotic agents; Acetylcholine.

\section{INTRODUCTION}

While the prevailing theory of tardive dyskinesia (TD) implicates supersensitivity of dopamine $D_{2}$-receptors $\left(D_{2} R\right)$ following prolonged drug-induced receptor blockade [1], evidence from clinical and preclinical research underscores limitations of this model [1-7]. While $D_{2} R$ supersensitivity may be a necessary initial trigger, advances in TD research depend on uncovering secondary downstream effects to identify alternative pharmacologic targets.

Received: July 6, 2020 / Accepted: July 8, 2020

Address for correspondence: Stanley N. Caroff

Behavioral Health Service, Corporal Michael J. Crescenz VA

Medical Center, Department of Psychiatry, University of

Pennsylvania Perelman School of Medicine, 3900 Woodland

Ave., Philadelphia, PA 19104, USA

E-mail: caroffs@pennmedicine.upenn.edu

ORCID: https://orcid.org/0000-0003-2840-4763
An alternative theory of reduced cholinergic activity within striatal motor circuitry serves as a rationale for treatments that normalize cholinergic signaling and restore reciprocal modulation between acetylcholine and dopamine [8]. Nigrostriatal dopamine attenuates acetylcholine release through activation of inhibitory $D_{2} R$ on cholinergic interneurons. $\mathrm{D}_{2} \mathrm{R}$ antagonists therefore release inhibitory effects of dopamine, elevating striatal acetylcholine [8] but eventually, chronic disinhibition and hyperactivity may damage cholinergic interneurons $[8,9]$ and decrease acetylcholine output. Clinical evidence supporting cholinergic deficiency in TD includes the fact that anticholinergic drugs worsen TD [10]. However, trials of precursors to restore acetylcholine activity in TD were disappointing because they were not absorbed by damaged cholinergic neurons or had nonspecific actions on multiple competing cholinergic receptor subtypes

(c) This is an Open-Access article distributed under the terms of the Creative Commons Attribution Non-Commercial License (http://creativecommons.org/licenses/by-nc/4.0) which permits unrestricted non-commercial use, distribution, and reproduction in any medium, provided the original work is properly cited. 
[11]. Subsequent trials of cholinesterase inhibitors to bypass damaged neurons and maximize synaptic acetylcholine yielded mixed results [11-13]. But nonspecific elevation of acetylcholine by cholinesterase inhibitors may also affect multiple acetylcholine receptor subtypes.

Recently, new research utilizing selective pharmaceutical tools allows for targeting specific acetylcholine receptors $[8,14]$. Since activation of nicotinic receptors (nAChR) releases striatal dopamine, nicotinic agonists should acutely worsen TD whereas long-term administration leading to $\mathrm{nAChR}$ desensitization may reduce dopamine release and suppress dyskinesias [15-17]. In fact, chronic administration of nicotine attenuates haloperidol-induced vacuous chewing movements in animal models $[17,18]$. Varenicline, a partial $n A C h R$ agonist, is even more effective [16]. However, effects of nicotine and varenicline on TD in humans is unclear [19]. Movement disorders have rarely been measured in clinical trials of varenicline [19-21]. Parkinsonism decreased with varenicline in one smoking cessation trial [22], but emerged after varenicline was initiated in a case report [23]. Another report described dyskinesias emerging in patients withdrawn from varenicline [24].

However, effects of varenicline on TD are confounded by cigarette smoking, which may affect movements in two ways [25]. Nicotine in cigarette smoke may activate $\mathrm{nAChRs}$ to release dopamine which would increase TD, while $\mathrm{nAChR}$ desensitization from chronic smoking may have the opposite effect $[15,25,26]$. Nicotine withdrawal after smoking cessation may reduce dopamine release and decrease TD. Secondly, hydrocarbons in cigarette smoke induce cytochrome enzymes CYP1A1, 1A2, and $2 \mathrm{E} 1$, significantly reducing plasma levels of several antipsychotics [25-27]. A decrease in antipsychotic levels while smoking may unmask or worsen TD $[25,26,28]$. Conversely, smoking cessation increases antipsychotic plasma levels which would suppress TD.

\section{METHODS}

To investigate the impact of varenicline on TD, we conducted an open-label, pilot study hypothesizing that TD would be reduced by both varenicline and smoking reduction (ClinicalTrials number NCT03495024).

\section{Patient Selection}

Three outpatients who met the following criteria were recruited; the Diagnostic and Statistical Manual of Mental Disorders 5th edition criteria for schizophrenia; diagnostic criteria for TD [29]; actively smoking based on cigarette consumption and exhaled carbon monoxide (CO); and no change in antipsychotic drugs for two months prior to screening. Approval was obtained from the Institutional Review Board at the Corporal Michael J. Crescenz VA Medical Center and written informed consent was obtained (ID \#: 01730, Prom \#: 0022).

\section{Procedures}

After a 2 week baseline period, patients underwent a 1 week period of titration of varenicline up to $1 \mathrm{mg}$ twice daily which they received for the remainder of participation. All patients were monitored on varenicline during a 4 week stabilization period. One subject was followed on varenicline for an additional 6 weeks after a pre-set quit date.

The primary outcome measure was the mean change in total score on the AIMS (items 1-7) from baseline to 4 weeks on varenicline, and to 10 weeks in one patient [30]. Primary outcome measure for smoking reduction was self-reported 7-day prevalence of daily mean cigarette use based on a questionnaire of time-line followback (TLFB) usage [31]. Secondary measures included $\mathrm{CO}$, parkinsonism and akathisia $[32,33]$. Descriptive results only are reported.

\section{RESULTS}

Three male patients (mean age \pm standard deviation $=$ $59.0 \pm 8.5$ years) with schizophrenia and TD who were receiving treatment with long-acting injectable paliperidone were recruited. Patients showed a significant decrease in mean daily cigarette consumption $(-6.3 \pm 4.5$ cigarettes/day) and $\mathrm{CO}(-6.0 \pm 9.4$ ppm) from baseline after receiving varenicline for 4 weeks (Tables 1, 2). There were no clinically significant changes from baseline observed in mean scores of TD $(1.0 \pm 2.2)$, parkinsonism $(-0.7 \pm 1.7)$ or akathisia $(0.3 \pm 0.5)$. Two patients were dropped after the stabilization period for unrelated symptoms and COVID-19 pandemic-related research restrictions. The other patient showed decreases in smoking only after his quit date, but no change in TD or akathisia. He 
Table 1. Patients receiving varenicline for smoking reduction and resulting effects on drug-induced movement disorders

\begin{tabular}{|c|c|c|c|c|c|c|c|c|c|}
\hline \multirow{2}{*}{$\begin{array}{c}\text { Patient, } \\
\text { Age }(y r) / S e x\end{array}$} & \multirow{2}{*}{$\begin{array}{c}\text { Diagnosis/ } \\
\text { Antipsychotic }\end{array}$} & \multirow[b]{2}{*}{ Measure } & \multicolumn{7}{|c|}{ Study visit } \\
\hline & & & $\begin{array}{l}\text { Screen } \\
\text { Week } 0\end{array}$ & $\begin{array}{l}\text { Baseline }^{a} \\
\text { Week } 2\end{array}$ & Week 3 & $\begin{array}{l}\text { Quit date } \\
\text { Week } 6\end{array}$ & Week 8 & Week 10 & Week 12 \\
\hline \multirow[t]{5}{*}{ 65/Male } & \multirow{5}{*}{$\begin{array}{l}\text { Schizophrenia/ } \\
\text { Paliperidone }\end{array}$} & TLFB $^{\mathrm{b}}$ & 7 & 20 & 20 & 10 & & & \\
\hline & & $\mathrm{CO}^{\mathrm{c}}$ & 18 & 7 & 10 & 5 & & & \\
\hline & & AIMS $^{d}$ & 16 & 12 & 17 & 14 & & & \\
\hline & & $\mathrm{SAS}^{\mathrm{e}}$ & 1 & 0 & & 1 & & & \\
\hline & & $\mathrm{BAS}^{f}$ & 6 & 5 & & 6 & & & \\
\hline \multirow[t]{5}{*}{ 47/Male } & \multirow{5}{*}{$\begin{array}{l}\text { Schizophrenia/ } \\
\text { Paliperidone }\end{array}$} & TLFB & 10 & 10 & 10 & 10 & 4 & 4 & 3 \\
\hline & & $\mathrm{CO}$ & 13 & 11 & 9 & 14 & 9 & 6 & 5 \\
\hline & & AIMS & 6 & 5 & 6 & 8 & 8 & 6 & 5 \\
\hline & & SAS & 10 & 9 & & 6 & & & 6 \\
\hline & & BAS & 5 & 5 & & 5 & & & 4 \\
\hline \multirow[t]{5}{*}{ 65/Male } & \multirow{5}{*}{$\begin{array}{l}\text { Schizophrenia/ } \\
\text { Paliperidone }\end{array}$} & TLFB & 14 & 14 & 8 & 5 & & & \\
\hline & & $\mathrm{CO}$ & 27 & 33 & 6 & 14 & & & \\
\hline & & AIMS & 4 & 6 & 4 & 4 & & & \\
\hline & & SAS & 0 & 0 & & 0 & & & \\
\hline & & BAS & 0 & 0 & & 0 & & & \\
\hline
\end{tabular}

${ }^{\mathrm{a}}$ Varenicline titration initiated at baseline, ${ }^{\mathrm{b}}$ Timeline-Follow Back mean daily cigarette consumption, ${ }^{\mathrm{c}}$ Carbon monoxide exhaled in parts per million (ppm), ${ }^{\mathrm{d}}$ Abnormal Involuntary Movement Scale, ${ }^{\mathrm{e}}$ Simpson Angus Scale, ${ }^{\mathrm{f}}$ Barnes Akathisia Scale.

Table 2. Mean \pm standard deviation changes in smoking and drug-induced movement disorders during 4-week stabilization on varenicline

\begin{tabular}{lccccc}
\hline & \multicolumn{3}{c}{ Study visit } \\
\cline { 2 - 6 } Measure & $\begin{array}{c}\text { Screen } \\
\text { Week 0 }\end{array}$ & $\begin{array}{c}\text { Baseline } \\
\text { Week 2 }\end{array}$ & Week 3 & Week 6 & $\begin{array}{c}\text { Change in mean scores } \\
\text { (Week 6-Week 2) }\end{array}$ \\
\hline TLFB $^{\mathrm{b}}$ & $10.3 \pm 2.9$ & $14.7 \pm 4.1$ & $12.7 \pm 5.2$ & $8.3 \pm 2.4$ & $-6.3 \pm 4.5$ \\
CO $^{\mathrm{c}}$ & $19.3 \pm 5.8$ & $17.0 \pm 11.4$ & $8.3 \pm 1.7$ & $11.0 \pm 4.2$ & $-6.0 \pm 9.4$ \\
AIMS $^{\mathrm{d}}$ & $8.7 \pm 5.2$ & $7.7 \pm 3.1$ & $9.0 \pm 5.7$ & $8.7 \pm 4.1$ & $+1.0 \pm 2.2$ \\
SAS $^{\mathrm{e}}$ & $3.7 \pm 4.5$ & $3.0 \pm 4.2$ & $-\mathrm{g}$ & $2.3 \pm 2.6$ & $-0.7 \pm 1.7$ \\
BAS $^{\mathrm{f}}$ & $3.7 \pm 2.6$ & $3.3 \pm 2.4$ & $-\mathrm{g}$ & $3.7 \pm 2.6$ & $+0.3 \pm 0.5$ \\
\hline
\end{tabular}

${ }^{\mathrm{a}}$ Varenicline titration initiated at baseline, ${ }^{\mathrm{b}}$ Timeline-Follow Back mean daily cigarette consumption, ${ }^{\mathrm{c} C a r b o n}$ monoxide exhaled in parts per million (ppm), ${ }^{\mathrm{d}}$ Abnormal Involuntary Movement Scale, ${ }^{\mathrm{e}}$ Simpson Angus Scale, ${ }^{\mathrm{f}}$ Barnes Akathisia Scale, ${ }^{\mathrm{g}}$ SAS and BAS were not performed at week 3.

did show a decrease in parkinsonism on varenicline which persisted 6 weeks after his quit date (Table 1).

\section{DISCUSSION}

Treatment with varenicline was associated with reduced smoking in three patients with schizophrenia, but no significant effect on mean ratings of TD, parkinsonism, or akathisia was detected. One patient who remained on varenicline for a total of 10 weeks after a pre-defined smoking quit date showed decreased scores for parkinsonism, which has been reported in a previous trial of varenicline [22]. These findings are preliminary and descriptive only pending controlled studies with larger samples.

Based on animal studies $[15,16]$, we anticipated that varenicline would reduce severity of TD. We also examined whether smoking reduction might contribute to TD suppression, by withdrawing nicotine-induced dopamine release or by restoration of hydrocarbon-depressed plasma levels of antipsychotics. But reduction in smoking was not associated with suppression of TD. However, all three patients were receiving long-acting paliperidone; it is uncertain whether metabolism of paliperidone is significantly affected by smoking-induced enzyme induction such that fluctuations in plasma levels probably were not a significant factor $[34,35]$. The results may have been different if patients received antipsychotics (e.g., clozapine) associated with marked increases in plasma levels after smoking reduction that would suppress TD. For this reason, clinical trials of TD should control for smoking status 
if antipsychotics affected by hydrocarbons are prescribed. Alternatively, paliperidone or other antipsychotics minimally affected by enzyme induction may be preferred for psychosis when smoking and TD are present.

There are several reasons why our findings conflict with reported efficacy of varenicline in suppressing dyskinesias in animal models [16]. We tested varenicline in patients with TD who smoke because smoking is highly prevalent among patients with mental illness and smoking cessation is its primary indication. Unlike our subjects, animals showing reduction in dyskinesias with varenicline were not nicotine dependent. It is possible that smokers already developed long-term effects of nicotine (e.g., nAChR desensitization) such that the effect of replacement with varenicline was muted. Parenthetically, if varenicline has no effect on TD in smokers, it may be preferred for smoking cessation when TD is present compared with bupropion which has been associated with worsening dyskinesias [36]. However, trials testing effects of varenicline on TD in nonsmokers remain important and may yield different results.

In addition, animal models of dyskinesias may be inexact substitutes for TD. There may be species differences in expression of nAChR subtypes and nAChR activity as well as response to varenicline [8]. There also may be differences in dosing and bioavailability. Although we used doses approved for smoking cessation, higher doses may be necessary to engage striatal targets to achieve changes in motor function. Duration of treatment may be relevant; the effectiveness of nicotinic agonists in animals depends upon long-term changes in plasticity since maximal therapeutic influence requires chronic administration suggesting that longer exposure to varenicline may have had a greater effect in our patients [18]. Although varenicline and nicotine may acutely stimulate dopamine release, longer-term administration may lead to nAChR desensitization, reducing dopamine release and acting as virtual dopamine antagonists by suppressing TD [16]. Disease stage, integrity of cholinergic interneurons and receptors, and chronicity have also been factors associated with diminished response to nicotinic agents in animal models. Our patients received long-term treatment with antipsychotics and had TD for several years; response may have been more favorable in patients with recent onset $\mathrm{TD}$, or if nicotinic agents were used prophylactically. Finally, outpatients recruited for the study may not have taken oral varenicline despite pill counts indicating compliance.

Future research on the mechanisms and treatment of TD should move beyond a limited focus on dopamine and translate insights gleaned from preclinical investigations of complex dynamics underlying striatal regulation of coordinated movement. These investigations are likely to uncover strategies based on neuronal circuitry that could be transformative in understanding TD. As more precise agents that target specific cholinergic receptors emerge, clinical trials in patients with TD may be worthwhile. In addition, smoking status and use of nicotine replacement therapies should be controlled in treatment trials of TD, and conversely, trials of varenicline and other nicotine replacement therapies should include measures of drug-induced movement disorders in patients receiving antipsychotic treatment.

\section{Acknowledgments}

Study drug was provided by Pfizer, Inc. as part of an Independent Investigator Initiated Research grant.

\section{Conflicts of Interest}

SC served as consultant for Neurocrine Biosciences Inc., Teva Pharmaceuticals Inc., Osmotica Pharmaceuticals, and Dispersol Technologies. SC also received a separate research grant from Neurocrine Biosciences Inc. Other authors report no financial conflicts.

\section{Author Contributions}

Conceptualization: Stanley N. Caroff. Data acquisition: Stanley N. Caroff, Alisa R. Gutman, John Northrop, Rosalind M. Berkowitz, E. Cabrina Campbell. Formal analysis: Stanley N. Caroff, Shirley H. Leong. Funding: Stanley N. Caroff. Supervision: Stanley N. Caroff, Shirley H. Leong, Rosalind M. Berkowitz, E. Cabrina Campbell. Writing-original draft: Stanley N. Caroff. Writing-review \& editing: Stanley N. Caroff, Alisa R. Gutman, John Northrop, Shirley H. Leong, Rosalind M. Berkowitz, E. Cabrina Campbell.

\section{ORCID}

Stanley N. Caroff https://orcid.org/0000-0003-2840-4763

Alisa R. Gutman https://orcid.org/0000-0002-4231-9090

John Northrop https://orcid.org/0000-0001-8676-8907

Shirley H. Leong https://orcid.org/0000-0003-2161-3466 
Rosalind M. Berkowitz

https://orcid.org/0000-0002-8828-6845

E. Cabrina Campbell

https://orcid.org/0000-0002-8198-2493

\section{REFERENCES}

1. Meyer JM. Future directions in tardive dyskinesia research. J Neurol Sci 2018;389:76-80.

2. Caroff SN, Davis VG, Miller DD, Davis SM, Rosenheck RA, McEvoy JP, et al. Treatment outcomes of patients with tardive dyskinesia and chronic schizophrenia. J Clin Psychiatry 2011; 72:295-303.

3. Caroff SN. Risk of neuroleptic malignant syndrome with vesicular monoamine transporter inhibitors. Clin Psychopharmacol Neurosci 2020;18:322-326.

4. Ward KM, Citrome L. Antipsychotic-related movement disorders: drug-induced parkinsonism vs. tardive dyskinesia-key differences in pathophysiology and clinical management. Neurol Ther 2018;7:233-248.

5. Jeste DV, Lohr JB, Kauffmann CA, Wyatt RJ. Pathophysiology of tardive dyskinesia; Evaluation of supersensitivity theory and alternative hypothesis. In: Casey DE, Gardos G, editors. Tardive dyskinesia and neuroleptics: from dogma to reason. Washington, D.C.:American Psychiatric Press; 1986. p.15-32.

6. Margolese HC, Chouinard G, Kolivakis TT, Beauclair L, Miller R. Tardive dyskinesia in the era of typical and atypical antipsychotics. Part 1: pathophysiology and mechanisms of induction. Can J Psychiatry 2005;50:541-547.

7. Mahmoudi S, Lévesque D, Blanchet PJ. Upregulation of dopamine D3, not D2, receptors correlates with tardive dyskinesia in a primate model. Mov Disord 2014;29:1125-1133.

8. Conti MM, Chambers N, Bishop C. A new outlook on cholinergic interneurons in Parkinson's disease and L-DOPA-induced dyskinesia. Neurosci Biobehav Rev 2018;92:67-82.

9. Miller R, Chouinard G. Loss of striatal cholinergic neurons as a basis for tardive and L-dopa-induced dyskinesias, neuroleptic-induced supersensitivity psychosis and refractory schizophrenia. Biol Psychiatry 1993;34:713-738.

10. Caroff SN, Campbell EC, Carroll B. Pharmacological treatment of tardive dyskinesia: recent developments. Expert Rev Neurother 2017;17:871-881.

11. Caroff SN, Campbell EC, Havey J, Sullivan KA, Mann SC, Gallop R. Treatment of tardive dyskinesia with donepezil: a pilot study. J Clin Psychiatry 2001;62:772-775.

12. Tammenmaa-Aho I, Asher R, Soares-Weiser K, Bergman $\mathrm{H}$. Cholinergic medication for antipsychotic-induced tardive dyskinesia. Cochrane Database Syst Rev 2018;3(3):CD000207.

13. Caroff SN, Walker P, Campbell C, Lorry A, Petro C, Lynch K, et al. Treatment of tardive dyskinesia with galantamine: a randomized controlled crossover trial. J Clin Psychiatry 2007; 68:410-415.

14. Bonsi P, Cuomo D, Martella G, Madeo G, Schirinzi T, Puglisi
$\mathrm{F}$, et al. Centrality of striatal cholinergic transmission in Basal Ganglia function. Front Neuroanat 2011;5:6.

15. Bordia T, Hrachova M, Chin M, Mclntosh JM, Quik M. Varenicline is a potent partial agonist at $\alpha 6 \beta 2 *$ nicotinic acetylcholine receptors in rat and monkey striatum. J Pharmacol Exp Ther 2012;342:327-334.

16. Quik M, Boyd JT, Bordia T, Perez X. Potential therapeutic application for nicotinic receptor drugs in movement disorders. Nicotine Tob Res 2019;21:357-369.

17. Quik M, Bordia T, Zhang D, Perez XA. Nicotine and nicotinic receptor drugs: potential for Parkinson's disease and drug-induced movement disorders. Int Rev Neurobiol 2015;124: 247-271.

18. Bordia T, McIntosh JM, Quik M. Nicotine reduces antipsychotic-induced orofacial dyskinesia in rats. J Pharmacol Exp Ther 2012;340:612-619.

19. Evins AE, Benowitz NL, West R, Russ C, McRae T, Lawrence $\mathrm{D}$, et al. Neuropsychiatric safety and efficacy of varenicline, bupropion, and nicotine patch in smokers with psychotic, anxiety, and mood disorders in the EAGLES trial. J Clin Psychopharmacol 2019;39:108-116.

20. Shim JC, Jung DU, Jung SS, Seo YS, Cho DM, Lee JH, et al. Adjunctive varenicline treatment with antipsychotic medications for cognitive impairments in people with schizophrenia: a randomized double-blind placebo-controlled trial. Neuropsychopharmacology 2012;37:660-668.

21. Smith RC, Amiaz R, Si TM, Maayan L, Jin H, Boules S, et al. Varenicline effects on smoking, cognition, and psychiatric symptoms in schizophrenia: a double-blind randomized trial. PLoS One 2016;11:e0143490.

22. Williams JM, Anthenelli RM, Morris CD, Treadow J, Thompson JR, Yunis C, et al. A randomized, double-blind, placebo-controlled study evaluating the safety and efficacy of varenicline for smoking cessation in patients with schizophrenia or schizoaffective disorder. J Clin Psychiatry 2012;73:654-660.

23. Uca AU, Kozak HH, Uğuz F, Gümüş H. Parkinsonism related to varenicline in a patient during smoking cessation. J Clin Psychopharmacol 2015;35:355-357.

24. Toffey BA, Rabin M, Kurlan R. Withdrawal-emergent dyskinesias following varenicline therapy. Open Neurol J 2015;9: 7-8.

25. Goff DC, Henderson DC, Amico E. Cigarette smoking in schizophrenia: relationship to psychopathology and medication side effects. Am J Psychiatry 1992;149:1189-1194.

26. George TP, Vessicchio JC, Termine A. Nicotine and tabacco use in schizophrenia. In: Meyer JM, Nasrallah HA, editors. Medical illness and schizophrenia. Arlington:American Psychiatric Publishing, Inc;2003. p.81-98.

27. Jin Y, Pollock BG, Coley K, Miller D, Marder SR, Florian J, et al. Population pharmacokinetics of perphenazine in schizophrenia patients from CATIE: impact of race and smoking. J Clin Pharmacol 2010;50:73-80.

28. Diehl A, Reinhard I, Schmitt A, Mann K, Gattaz WF. Does the 
degree of smoking effect the severity of tardive dyskinesia? A longitudinal clinical trial. Eur Psychiatry 2009;24:33-40.

29. Glazer WM, Morgenstern H, Doucette JT. Predicting the long-term risk of tardive dyskinesia in outpatients maintained on neuroleptic medications. J Clin Psychiatry 1993;54:133139.

30. Guy W. Abnormal Involuntary Movement Scale (II7-AIMS). In: Guy W, editor. ECDEU assessment manual for psychopharmacology. Rockville:Alcohol Drug Abuse and Mental Health Administration; 1976. p.534-537.

31. Brown RA, Burgess ES, Sales DS, Whiteley JA, Evans DM, Miller IW. Reliability and validity of a smoking timeline follow-back interview. Psychol Addict Behav 1998;12:101-112.

32. Simpson GM, Angus JW. A rating scale for extrapyramidal side effects. Acta Psychiatr Scand Suppl 1970;212:11-19.

33. Barnes TR. A rating scale for drug-induced akathisia. Br J Psychiatry 1989;154:672-676.

34. de Leon J, Wynn G, Sandson NB. The pharmacokinetics of paliperidone versus risperidone. Psychosomatics 2010;51: 80-88.

35. Schoretsanitis G, Haen E, Stegmann B, Hiemke C, Gründer G, Paulzen M. Effect of smoking on risperidone pharmacokinetics - a multifactorial approach to better predict the influence on drug metabolism. Schizophr Res 2017;185:51-57.

36. Tuman TC, Çakır U, Yıldırım O, Camkurt MA. Tardive dyskinesia associated with bupropion. Clin Psychopharmacol Neurosci 2017;15:194-196. 